\title{
Un comerciante navarro dueño de los bosques de la costa oriental de Yucatán: Faustino Martínez (1889-1909)
}

\section{A Navarrese Merchant Owner of the East Coast of Yucatan's Forests: Faustino Martinez (1889-1909)}

\author{
Edgar J. Rangel \\ Centro de Investigaciones y Estudios Superiores \\ en Antropología Social, Yucatán, México, \\ email: ejrango@gmail.com
}

\begin{abstract}
Resumen. A través del recuento histórico del empresariado en la explotación forestal de los bosques en la costa oriental de Yucatán, se reconstruye la figura de Faustino Martínez, hombre de negocios que representa a la oligarquía económica mexicana del porfiriato, y cuyo perfil empresarial le permitió emprender negocios y acciones para aprovechar las concesiones en el oriente de la península yucateca. El acceso que tuvo a las altas esferas, económica y política, nos permite conocer la trascendencia de este español a partir de sus nexos y negocios en la región, lo que le permitió obtener vastas propiedades, autorizaciones forestales, atraer la fuerza de trabajo y establecer una economía de extracción para coadyuvar a la constitución del territorio federal de Quintana Roo.
\end{abstract}

Palabras clave: porfiriato; empresariado; sociedades mercantiles; explotación forestal; historia económica regional.

Abstract. Through the historic review of the Eastern Coast of Yucatan forests logging entrepreneurship, Faustino Martínez's figure is reconstructed, business man who represents the Porfiriato's Mexican economic oligarchy, his business profile allowed him undertake business and actions to take advantage over the forest concessions in the east of the Yucatan Peninsula. The access he has to the highest economic and political spheres, is the key to know the transcendence of this Spaniard entrepreneurship on the basis of his links and business in the region, which enable to obtain longest properties, greatest forest authorizations, to move labor force and to establish an extraction economy in order to built the Quintana Roo Federal Territory.

Key words: Porfiriato; entrepreneurship; extractive industries; trade; micro-business history.

JEL: N56, N76, N86

Am. Lat. Hist. Econ., sept.-dic., 2018, pp. 160-186 | DOI: 10.18232/alhe.927 
Fecha de recepción: 28 de septiembre de 2017. Fecha de aceptación: 26 de enero de 2018.

Organismos colaboradores: Programa de Becas Nacionales del Consejo Nacional de Ciencia y Tecnología.

\section{INTRODUCCIÓN}

$\mathrm{E}$ 1 objetivo del presente trabajo es analizar la figura del hombre de negocios español Faustino Martínez, las acciones del empresario, su trayectoria empresarial y su pertenencia al empresariado porfiriano, teniendo como eje conductor sus vínculos con los principales capitales españoles establecidos en México, sus alianzas con el sector rector de la economía, de sus nexos con funcionarios de alto nivel, de los intereses, los retos y las oportunidades de negocio que lo llevan a trascender en la economía nacional y yucateca. La trayectoria de Martínez muestra su afán de lucro para beneficiarse de la economía de explotación de materias primas para satisfacer el mercado internacional, su participación en el grupo que dirige la economía del país que utiliza el desarrollo capitalista que promueve el régimen porfiriano y el contubernio con el gobierno federal para consolidar los intereses de los grandes inversionistas por encima de los actores regionales. A partir de los señalamientos de Jean-Baptiste Say y Joseph Chumpeter (en Cardoso, 1978, p. 14), no consideramos a Faustino Martínez como el empresario que interviene de manera directa en la formación de precios o de los procesos productivos, tampoco fue el responsable de la innovación de procedimientos o mercados, ni como motor del progreso del país, pero sí participa en el proceso sentado por la política y la paz porfirianas para imponer el progreso económico, en una primera instancia en negocios mercantiles y posteriormente en actividades que coadyuvan a la inserción de México como proveedor de materias primas para el mercado internacional. Es precisamente el acceso que logra en las altas esferas económica y política donde se puede percibir la trascendencia de este personaje al poseer tierras, en disputa por su control y usufructo, que lo convierten en el dueño de los bosques de la costa oriental de Yucatán, una región de frontera-borde forestal. Con ello, el empresario navarro compite y supera a destacados hombres de negocios de la economía henequenera yucateca como Olegario Molina Solís y Eusebio Escalante y Bates. Además, las autorizaciones y las acciones que emprende coadyuvan a la constitución del territorio federal de Quintana Roo erigido a inicios del siglo pasado.

Este empresario constituye una pieza más en la historia económica para contribuir, conocer y comprender el proceso de formación y desa- 
rrollo de la burguesía mexicana durante las últimas décadas del siglo XIX, cuya fidelidad hacia el régimen porfiriano significa relaciones de lealtad y preferencia. En el caso de Martínez, se percibe un silencioso impacto a pesar de haber estado en el país durante tres décadas hasta su temprana muerte en 1909. Además, la historia quintanarroense no puede ser abordada sin mencionar el nombre de Faustino Martínez, personaje calificado por la prensa capitalina de finales del siglo XIX como el dueño de Yucatán y en la centuria pasada como un terrateniente bajo el fervor revolucionario, resaltado en textos elaborados en la década de 1980 sobre Quintana Roo. Así como también los realizados a finales de la década de 1990, trabajos histórico-antropológicos que no se centran en el actuar del empresariado, la conformación de las sociedades forestales y sus modelos productivos (César y Arnaiz, 1983; 1984; 1990; Higuera, 1997; Macías, 1997). En la década pasada son las investigaciones de Gabriel A. Macías (2002) y Martha H. Villalobos (2006) las que analizan el ciclo forestal que se realizó en la zona durante el porfiriato, en el proceso de la conformación marítima, social y forestal quintanarroense. Así como también la participación de los pueblos mayas sublevados (del oriente y del suroriente) y los intereses de los comerciantes-madereros ingleses establecidos en Honduras británica (Belice). Pero no se otorga al empresario navarro la importancia que pretendemos resaltar en este trabajo de historia empresarial regional, como ha sido el caso de los yucatecos Olegario Molina o Eusebio Escalante, ${ }^{1}$ quienes destacan por su control en la agroexportación henequenera, la banca y los ferrocarriles de la entidad.

A pesar de que Faustino Martínez no se destaca por el monto de su fortuna, lo podemos relacionar con el grupo de inversionistas que se valen de la política económica y la paz porfirianas para promover el desarrollo capitalista del país, aunque en la historiografía permanece a la sombra de sus principales amigos y socios como Ignacio de la Torre, Iñigo Noriega o Thomas Braniff, sobresale por las empresas constituidas con estos y por los nexos logrados con miembros de alto nivel del gabinete porfiriano como Manuel Dublán, Carlos Pacheco y José Y. Limantour. Pero más allá, se trata de un integrante del empresariado porfiriano que participa en sociedades de la época, como fueron la Compañía Colonizadora de la

${ }^{1}$ A pesar de la vasta historiografía de la región económica del oriente yucateco decimonónico, no se han realizado investigaciones relativas a la participación del empresariado forestal durante la era porfiriana y las primeras décadas del siglo pasado, se han centrado en la comercialización del henequén, el establecimiento de la banca, el desarrollo de las vías férreas y la explotación de recursos forestales en la costa oriental de Yucatán, el caso de Molina Solís y Escalante y Bates. Respecto a Felipe Ibarra Ortoll ha sido objeto de mención en algunos textos. En el caso de Antonio Espinosa Rivas, Manuel José Sierra Méndez, José Ramón Ancona Bolio y Faustino Martínez, existen pocas investigaciones, entre las más destacadas, Macías (2002), Rangel (2014), y Villalobos (2006). 
Costa Oriental de Yucatán, el Banco de Londres y México, la Compañía Agrícola del Xico, la Compañía del Ferrocarril de Xico y San Rafael, la Compañía de los Ferrocarriles Sud-Orientales en Yucatán, entre otras. Su oportunidad de negocios en la ciudad de México, el área conurbada y la península yucateca le permite llevar a cabo diversas actividades. Lo más trascendente de este empresario navarro es poseer $15.6 \%$ del territorio del estado de Yucatán donde desarrolla sus negocios agrícola-forestales en el contexto de la fragmentación de la península con la creación del territorio federal quintanarroense, del cual posee $28.5 \%$. Es por ello que se destaca por ser el mayor beneficiario del sistema de concesiones y por desarrollar la economía de explotación de recursos forestales por medio de las sociedades anónimas más notorias que contribuyeron a la economía capitalista de la época, Faustino Martínez y Cía. y la Compañía Colonizadora de la Costa Oriental de Yucatán, que destacan su importancia a diferencia de las actividades realizadas en el noroeste henequenero y de la zona controlada por la plantocracia yucateca.

El afán de lucro del empresario navarro le lleva a diversificar sus inversiones en actividades productivas, estableciendo así una manera de asociarse y hacer negocios por medio de empresas modernas capitalizadas con acciones, encabezadas por consejos directivos y administrativos, controladas por los principales accionistas (Valerio, 2003, p. 66). Se constituyen así, emporios económicos que simulan a los grandes trusts estadunidenses, cuyos integrantes, socios, accionistas y miembros consultivos ocupan lugares clave de la vida política, económica, social y cultural de la república mexicana y de ciertas regiones como la península de Yucatán.

El trabajo está divido en tres partes, siendo la primera una aproximación al perfil empresarial de Martínez, su llegada a México, sus primeros vínculos económicos con la comunidad española y sus negocios mercantiles en la capital de la república mexicana, proceso donde observamos un vertiginoso ascenso en la década de 1880; al conformar el grupo de inversionistas se incorpora al Banco de Londres y otras sociedades en las que funge como accionista y miembro consultivo junto a diversos personajes de la economía porfiriana. En el segundo apartado se analiza la participación del empresario navarro Martínez en el sistema de concesiones forestales, cuyas autorizaciones le permitieron desarrollar la economía de extracción y convertirse en el dueño de los bosques de la costa oriental de Yucatán. En la tercera parte se analiza la participación de Martínez en una de las más importantes sociedades de la economía porfiriana, la Compañía Colonizadora de la Costa Oriental de Yucatán, cuya gerencia ocupa por casi diez años y logra la diversificaron de inversiones o la construcción de las primeras vías férreas en la región, contexto en el que coincide el declive de la explotación forestal en el territorio federal de Quintana Roo. 
Cabe destacar la presencia de los empresarios que inmigraron a México, en especial los de origen español, cuya trascendencia y participación en la economía mexicana de los siglos XIX y XX se pueden observar en estudios sobre el empresariado textil de origen español en la ciudad de México y su periferia o los que destacan los empresarios vascos en el capitalismo mexicano. En cuanto a Faustino Martínez, nace el 18 de mayo de 1858 en Navarra, España, y muere el 24 de junio de 1909 en la ciudad de México. Su arribo al puerto de Veracruz lo realiza en el buque Alfonso XII procedente de La Habana, Cuba, en abril de $1879 .{ }^{2}$ Su llegada al país responde a la tradición española de realizar la inmigración en cadena para hacerse cargo de los negocios familiares (Lida, 1981, p. 13), ya que su hermano Juan Bautista Martínez ${ }^{3}$ es un respetable e importante comerciante en Puebla y la capital de la república mexicana. Desde un inicio Faustino se vincula con destacados miembros de la colonia española como Francisco Zaldívar, Baldomero Prida, Félix Cuevas, Delfín Sánchez, Antonio Basagoiti, los hermanos Iñigo y Remigio Noriega, entre otros.

$\mathrm{El}$ empresario navarro establece su primera sociedad mercantil el 15 de diciembre de 1881, Faustino Martínez y Cía., en la que se asocia con los españoles Francisco Zaldívar y Baldomero Prida. La empresa cuenta con un capital social de 21000 pesos que aportan Martínez (5 000 pesos) y Zaldívar (16 000 pesos), mientras Prida funge como socio industrial y encargado de la tienda La Pasamanería, dedicada a la comercialización de abarrotes, productos nacionales e importados, pinturas, ornamentos, cordones, borlas y galones para carruajes. ${ }^{4}$ Su relativo éxito en los primeros años se logra por estar en la misma zona donde estaban establecidos joyeros, restauranteros, camiseros, confiteros, sastres, cajoneros y comerciantes de confecciones y novedades, pues el negocio se ubicaba en la calle de San Bernardo (hoy Venustiano Carranza) número 5, en la estratégica zona comercial del centro de la ciudad de México. Pero a mediados de 1884 la administración de Prida propicia problemas financieros, por lo que

${ }^{2}$ Le Trait d'Unión, 13 de abril de 1879, p. 3.

${ }^{3}$ Originario de Navarra, Juan B. Martínez arriba al puerto de Veracruz en agosto de 1861 para radicar en Chalchicomula, Puebla, donde ocupa una curul como diputado local y forma parte de la Junta Proveedora. A su traslado a la ciudad de México destaca como uno de los más importantes empresarios cigarreros con su fábrica El Modelo, fundada en 1884. Además, dirige el periódico El Correo Español hasta finales de 1887 y es partícipe en asociaciones como la Sociedad de Beneficencia, la Junta Patriótica, la Cámara Española de Comercio y el Casino Español (Rangel, 2014, pp. 336-337).

${ }^{4}$ Conformación de la sociedad Faustino Martínez, 15 de diciembre de 1881, ciudad de México, Fondo Antiguo (en adelante FA), vol. 642, ff. 453-454. Acervo Histórico de Notarías (en adelante AHN). El Monitor Republicano, 14, 15, 16 y 26 de octubre y 9 y 18 de noviembre de 1883. 
los socios de Martínez se retiran y este queda a cargo de los pasivos (2 471 pesos), activos y la liquidación de los accionistas. ${ }^{5}$

Martínez aprovecha la oportunidad de negocio como proveedor de bienes de consumo, así como sus vínculos familiares y amistosos, para formar parte de la nueva generación de empresarios que crean casas mercantiles. Su trayectoria comercial lo involucra con la elite que aparece en la prensa liberal de la época, que ostenta su fortuna en eventos sociales, que asiste a banquetes y bailes de palacio nacional, que conforma los clubes o asociaciones de empresarios destacados como el Casino Español o el Jockey Club. Nuestro empresario se hace presente en diversos eventos sociales que el empresariado español y la alta sociedad mexicana realizaban, pues algunos diarios de la ciudad de México reportan su asistencia a varios bailes, banquetes, cenas o reuniones con altos funcionarios del gabinete porfiriano, diplomáticos o los más renombrados hombres de negocio, como el que Martínez ofreció en honor a Pablo Macedo en $1903 .{ }^{6}$ La "aristocracia de la industria, el comercio y los servicios" que se gesta a finales del siglo XIX en México (González, 2010, p. 51).

Observamos que el empresario navarro participa en la sinergia existente entre el grupo de capitalistas extranjeros avecindados en el país y altos funcionarios de la burocracia porfiriana, su círculo de amistades y socios se extiende a personajes como el yerno del presidente Ignacio de la Torre y Mier, el magnate Thomas Braniff, el banquero Henry Campbell Waters, comerciantes como Ricardo Sáinz, Manuel Ibáñez, los hermanos Bermejillo, Manuel Romano Gavito, Valentín Encoro, Telésforo García, Antonio Basagoiti, Rafael Dondé, Guillermo Barrón, Justo Benítez, Pablo Escandón y Casimiro Pacheco, Manuel Paredo, J. Martel, Indalecio Sánchez Gavito, Indalecio Ibáñez, Ruperto Crespo, los barcelonnettes León Signoret, León Honorat, Jules y Henri Tron, Joseph y Antoine Olliver,

\footnotetext{
${ }^{5}$ Aunque las utilidades y pérdidas se reparten entre los tres socios (Martínez, 40\%; Zaldívar, 35\%; Prida, 25\%) el 25 de julio de 1884 se lleva a cabo la separación legal y Faustino Martínez paga 19038.19 pesos a Zaldívar por concepto de pérdidas y 1000 pesos a Prida por saldo de toda cuenta de liquidación. A inicios de 1887 los abogados de Martínez, Vidal Castañeda y Nájera y Francisco Cosío, logran la exoneración de su representado y no se tuvo que pagar más a la viuda de Prida. Véase Disolución de la sociedad Faustino Martínez, ciudad de México, 25 de julio de 1884, FA, vol. 65, ff. 57-58, AHN. Modificación de la sociedad Faustino Martínez, 29 de agosto de 1884, ciudad de México, FA, vol. 65, ff. 163-164, AHN.

${ }^{6}$ La revisión hemerográfica señala la participación del empresario español en bailes y cenas celebrados por su camarilla, como el efectuado el 23 de abril de 1898 por Thomas Braniff en honor del presidente Porfirio Díaz y su esposa. En el banquete ofrecido a Macedo, encontramos la asistencia de José Sánchez Ramos, Telésforo García, Fernando Pimentel y Fagoaga, Manuel Pereda (director del Banco Nacional), Indalecio Sánchez Gavito, Adolfo Prieto, Antonio Barrios, Gonzalo de Murga, Juan Servín, Manuel Suárez, Indalecio Ibáñez, Ruperto Crespo y otros (The Mexican Herald, 23 de abril de 1898, p. 8; The Two Republics, 24 de abril de 1898, p. 5; "Un banquete en honor del Sr. Macedo", El Imparcial, 12 de julio de 1903, p. 2).
} 
científicos como Adolfo Prieto, Pablo Macedo, Manuel Dublán, Justo y Manuel Sierra Méndez, Manuel y Francisco González Cosío, José y Julio Limantour, Hugo Scherer, Porfirio Díaz hijo, el coronel Manuel Alarcón, el general José María de la Vega, entre otros. Es así que Martínez, quien se ubica en la punta de la pirámide social, se benefició del apoyo que brindó al régimen porfiriano por medio de las sociedades de amigos del presidente o el círculo de amigos del general Porfirio Díaz, organizaciones dedicadas a apoyar y hacer propaganda al régimen (Arias, 1999, pp. 54101; Collado, 1987; Guerra, 2012; Pérez-Rayón, 1995).

Es en la ciudad de Mérida donde Martínez vislumbra la oportunidad de incursionar en el ramo financiero de la floreciente economía henequenera al utilizar la oportunidad que le otorga el gobierno mexicano al extenderle una concesión para establecer el Banco Agrícola e Industrial Yucateco en la capital yucateca en 1889. Entre sus atribuciones se destacan emitir moneda, realizar operaciones financieras, generar cuentas corrientes, recibir depósitos y otorgar créditos para agricultores e industriales que hasta ese momento no contaban con una institución crediticia. Pero en marzo de 1890, el concesionario español no realiza el depósito de 30000 pesos (Secretaría de Hacienda y Crédito Público, 1891, pp. 79-83). ${ }^{7}$ Los intereses de Martínez se ven limitados debido a los grandes intereses de la plantocracia yucateca acostumbrados a emitir vales al portador e interesados por establecer sus propios bancos. ${ }^{8}$ Este tropiezo no impide a Martínez estrechar vínculos con Eloy Haro, Rafael Peón, Ángel y Policarpo Rivas, Juan y Olegario Molina o Felipe Ibarra Ortoll, todos hombres de negocios de la península de Yucatán dedicados al comercio al por mayor, la agroexportación, el transporte marítimo y los bienes raíces.

A mediados de la década de 1890, el empresario navarro participa en las más importantes sociedades anónimas de colonización, forestales, agrícolas, financieras, de transporte y la adquisición de terrenos en la ciudad de México y la costa oriental de Yucatán, región donde lleva a cabo sus negocios más importantes a través de los consorcios F. Martínez y Cía. y la Compañía Colonizadora de la Costa Oriental de Yucatán, como veremos en los siguientes apartados. Pero en la capital del país, en asociación con Iñigo Noriega, Martínez participa en el proyecto de fraccionamiento de terrenos que conforman la colonia de Santa María de la Ribera. ${ }^{9}$ En octubre

\footnotetext{
${ }^{7}$ Banco Agrícola Yucateco. La Revista de Mérida, 30 de marzo de 1897, p. 2. El contrato se firmó el 24 de mayo de 1889, se señalaba que la institución financiera debería de contar con un capital social mínimo de 500000 pesos representado en acciones de 100 pesos cada una.

${ }^{8}$ Como fueron el Banco Yucateco y el Banco Mercantil Yucateco.

${ }^{9}$ El 6 de enero de 1893, Juan Dublán compra a Martínez un terreno de 4011 metros cuadrados en la colonia Santa María de la Ribera, propiedad fraccionada y vendida a Carlos Tamborrel, Carlos Sellerier, Agustina Gual de Stelling, Isabel Coiffier de Derbesy, entre otros. Venta de te-
} 
de 1896 el empresario navarro, junto con un grupo de capitalistas galos, españoles y algunos científicos mexicanos, participa en el incremento del capital social de la primera institución financiera establecida en el país, el Banco de Londres y México, en donde conforma la mesa directiva al lado de apellidos como Braniff, González, De la Torre, Waters, Signoret, Noriega, Tron, Elcoro, Ollivier, Michel, Honorat, Sánchez Ramos, Romano Gavito, Hauser, Espinosa, Lamber, Barroso, Suinaga, Guinchard y Albaitero (Banca Serfin, 1995, p. 40; Banco de Londres, 1964, p. 57; Pérez de Sarmiento, 2004, pp. 112-113). ${ }^{10}$

Además de destacar por sus negocios económicos y participar en el entorno financiero de la economía porfiriana, encontramos a Martínez en otras importantes sociedades: la Compañía Agrícola del Xico, la Compañía Papelera San Rafael y la Compañía del Ferrocarril de Xico y San Rafael, establecidas bajo la batuta de los españoles Basagoiti y los hermanos Noriega, cuyas concesiones les permiten desecar el lago de Chalco y usufructuar los ricos terrenos de cultivo de Xico. ${ }^{11}$ En estas sociedades encontramos los mismos apellidos del empresariado que integra el banco londinense, pero destacamos la participación de Faustino Martínez en los consejos de administración y por ser el dueño de 500 acciones con valor de 100 pesos cada una, que representaron 16\% del capital social, constituyéndose junto con Braniff, Waters, Basagoiti, Sánchez, Barroso y Richaud como los propietarios más importantes de las negociaciones. ${ }^{12}$ En este contexto, los intereses de Martínez en la península yucateca lo llevan a interesarse en el establecimiento de nuevos caminos de fierro que comuniquen sus posesiones en el oriente con los puntos de auge económico como Valladolid, Mérida y el puerto de Progreso, por lo que participa como accionista de la Compañía de los Ferrocarriles Sud-Orientales en Yucatán. ${ }^{13}$

\section{Aparece El DUEÑo de los Bosques de la COSTA ORIENTAL de YuCATÁN}

Uno de los principales negocios de Faustino Martínez es el deslinde, ocupación y explotación de los terrenos y bosques existentes en la costa oriental de Yucatán al observar la oportunidad de negocio como proveedor

rrenos de Juan Dublán en Santa María la Ribera, 25 de marzo al 21 de mayo de 1895, ciudad de México, FA, vol. 7, libro 69, ff. 146-321, AHN.

${ }^{10}$ The Mexican Herald, 22 de octubre de 1896, p. 8.

${ }^{11}$ The Mexican Herald, 18 de agosto de 1897, p. 1; El Popular, 20 de agosto de 1897, p. 2; El Tiempo, 26 de agosto de 1897, p. 1.

${ }^{12}$ Escritura de la negociación agrícola de Xico y anexas, S. A., 1 de julio de 1897, ciudad de México, Fondo Contemporáneo, libro 1, f. 2, AHN.

${ }^{13}$ Compañía de los Ferrocarriles Sud-orientales en Yucatán: concesiones y estatutos, Mérida, 1900, Fondo Ferrocarriles, número E, ficha 18581, clasf. F, p. 41. Biblioteca Yucatanense. 
de materias primas al mercado internacional. Su afán de lucro le permite ser partícipe del sistema de concesiones forestales que otorga el gobierno mexicano y afronta lo retos que representa esta región de frontera-borde forestal donde se beneficia, junto con sus socios. Por su situación adyacente a las posesiones inglesas de Honduras británica y por ser una zona de guerra con los mayas sublevados, la región indómita y semidespoblada del oriente yucateco la concebimos como un espacio resultado del proceso histórico, la imbricación de sucesos, intereses y actores, en donde se disputa el control territorial, el usufructo de recursos maderables, la demarcación fronteriza, y se consolida el territorio federal de Quintana Roo en los albores del siglo Xx. Se trata de una región de frontera forestal con extensión de 50000 kilómetros cuadrados, rica en recursos maderables para la construcción, la ebanistería y la tintórea -caoba, cedro, palo de tinte, chicozapote, jabín, entre otras-, que conforman la economía de extracción y que la insertan en el mercado internacional como proveedor de materias primas desde el siglo XVII hasta mediados de la centuria pasada. Un espacio donde se presentaron los intereses de los comerciantes-madereros ingleses, los mayas orientales, los empresarios yucatecos y campechanos, que gracias a la estabilidad lograda por la política y la paz porfirianas se logran establecer marcadores económicos de soberanía (Nelken-Terner, 1997, pp. 148-166; Rangel, 2014, pp. 4-6) a partir de las autorizaciones otorgadas por el sistema de concesiones que beneficia a ciertos empresarios. Estos marcadores son un conjunto de elementos vinculados, la existencia de recursos naturales y tierras, un régimen político estable, el andamiaje legal necesario para ordenar las relaciones y actividades económicas, el capital nacional y extranjero, el afán de lucro y el usufructo que mostraron Felipe Ibarra Ortoll, Manuel J. Sierra, Faustino Martínez, The Stamford Manufacturing Co., Rafael Peón, Olegario Molina, Rodolfo Reyes y John E. Plummer. Todos estos aspectos favorecieron la negociación del Tratado Mariscal-St. John y la confirmación del borde limítrofe del sureste mexicano en 1898.

Es Faustino Martínez el que logra apropiarse de los bosques y consolidar los circuitos comerciales forestales a favor de la economía mexicana, afrontando los retos que representan la guerra social de los mayas sublevados y los cortes furtivos de los madereros ingleses de Honduras británica. Entre 1889 y 1893, el empresario navarro logra el deslinde, la propiedad y la explotación de un vasto terreno entre cabo Catoche y Tulum, el más importante realizado en la zona, logra así lo que sus predecesores, Ibarra, Sierra y Antonio Espinosa no pudieron, al convertirse en el dueño de 7232 kilómetros cuadrados de tierras y sus bosques en la costa oriental de Yucatán (véase mapa 1), cuyo valor se estima en 361625 pesos. Además, en 1898 se le otorga una autorización para el arrendamiento de un terreno 
nacional con extensión de 7000 kilómetros cuadrados en las márgenes del río Hondo por la que paga 350000 pesos, en la que lleva a cabo el usufructo de recursos maderables (véase mapa 2). ${ }^{14}$ Con ambas concesiones el empresario navarro controla 14232 kilómetros cuadrados de la península yucateca, $15.6 \%$ de la entidad. De hecho, ningún otro terrateniente del sureste mexicano como Olegario Molina, Eusebio Escalante, Ramón Ancona, Policarpio Valenzuela, Luis Hüller o los hermanos Bulnes, tienen bajo su control tal extensión de terrenos. ${ }^{15}$ De ahí que Faustino Martínez es considerado el dueño de Yucatán por la prensa capitalina. ${ }^{16}$ Si para ese entonces el gestor campechano Manuel Sierra Méndez se autodenomina el marqués de Cozumel, ${ }^{17}$ el empresario navarro se gana la alegoría con el duque de Westminster sir Hugh Grosvenor, quien en la misma época era el dueño de medio Londres. ${ }^{18}$ Además, al ser un personaje ligado a la presidencia de la república, sus posesiones y actividades extractivas son idóneas para el proyecto de creación de un territorio federal que se consolida en 1903, Quintana Roo, pues es dueño de 28.4\% de los bosques de la costa oriental de Yucatán.

\section{EXPLOTACIÓN FORESTAL Y AGRÍCOLA COMO NEGOCIO PRINCIPAL DEL DUEÑO DE LOS BOSQUES DE LA COSTA ORIENTAL DE YUCATÁN}

Durante la primera mitad de la década de 1890, el empresario español dueño de los bosques de la costa oriental de la península yucateca aprovecha el negocio y desarrolla su afán de lucro en la zona a través de dos en-

${ }^{14}$ La Concesión de Río Hondo se localiza junto a la concesión de la sociedad estadunidense The Stamford Manufacturing Co., en la zona donde convergieron los linderos mexicano e inglés. Nota de la Secretaría de Fomento a la de Relaciones Exteriores notificando la información de los terrenos concesionados al Sr. Faustino Martínez, para la explotación de maderas de construcción, ebanistería y tinte, así como para la extracción de gomas y resinas de todos los árboles que existan en una porción de terrenos baldíos y nacionales en el Estado de Yucatán, 1 de julio de 1898, ciudad de México, 14 de julio de 1899, leg. 44-12-54, 1 f. Archivo Histórico Genaro Estrada (AHGE).

${ }^{15}$ Para la década de 1880 , en la costa oriental de la península yucateca encontramos las posesiones de Antonio Espinosa Rivas con 119 kilómetros cuadrados frente a la isla de Holbox, Manuel J. Sierra con 265 kilómetros cuadrados en las islas de Cozumel y Mujeres, Prudencio Hijuelos y Filiberto I. Méndez con 25 kilómetros cuadrados cada uno en isla Mujeres y José Ramón Ancona Bolio con 970 kilómetros cuadrados en El Cuyo. En Tabasco, P. Valenzuela posee 7433 kilómetros cuadrados y en Chiapas, Bulnes Hermanos y Luis Hüller tienen en posesión $401 \mathrm{y}$ 2880 kilómetros cuadrados, respectivamente.

${ }^{16}$ Los terrenos de D. Faustino Martínez, La Revista de Mérida, 14 de marzo de 1896, p. 2.

${ }^{17}$ La alusión al marqués de Cozumel es tomada de la conversación transcrita entre el general Rafael E. Melgar, jefe de gobierno del territorio federal de Quintana Roo, y Luis Rosado Vega en la década de 1930, sobre las posesiones de Sierra Méndez (Rosado, 1940, p. 41).

18 "El dueño de la tercera parte de Londres", El Tiempo, 29 de febrero de 1896, p. 1; "Un émulo del duque de Westminster", El Tiempo, 24 de marzo de 1896, p. 2. 


\section{MAPA 1. TERRENOS DE FAUSTINO MARTÍNEZ Y CÍA. EN LA COSTA ORIENTAL DE YUCATÁN (1890-1909)}

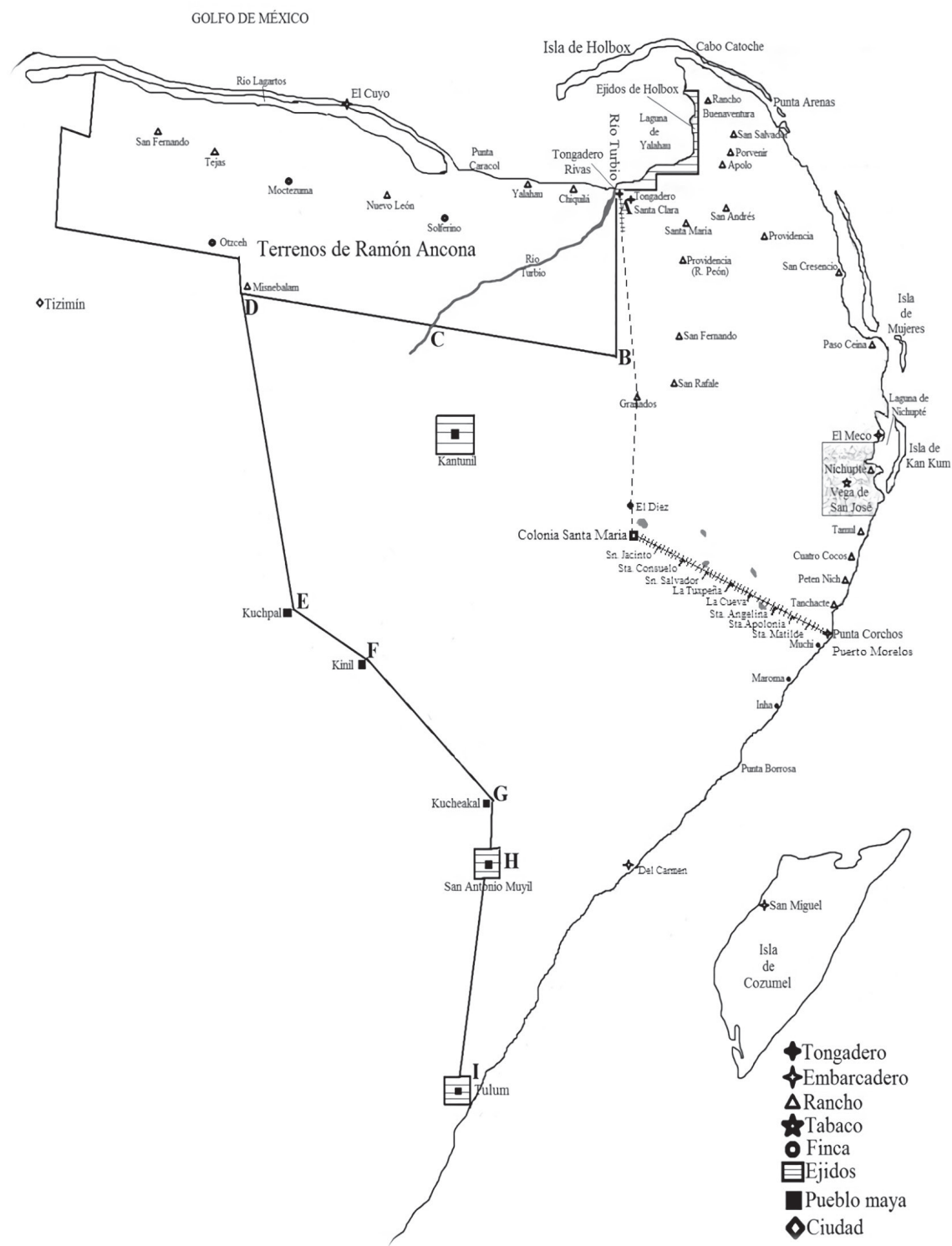

Fuente: elaboración propia con base en Acta Constitutiva de la Compañía Colonizadora de la Costa Oriental de Yucatán, S. A., 2 de marzo de 1896, ciudad de México, FA, vol. 21, s. f., AHN. 


\section{MAPA 2. SISTEMA DE CONCESIONES FORESTALES} EN EL TERRITORIO FEDERAL DE QUINTANA ROO (1903)

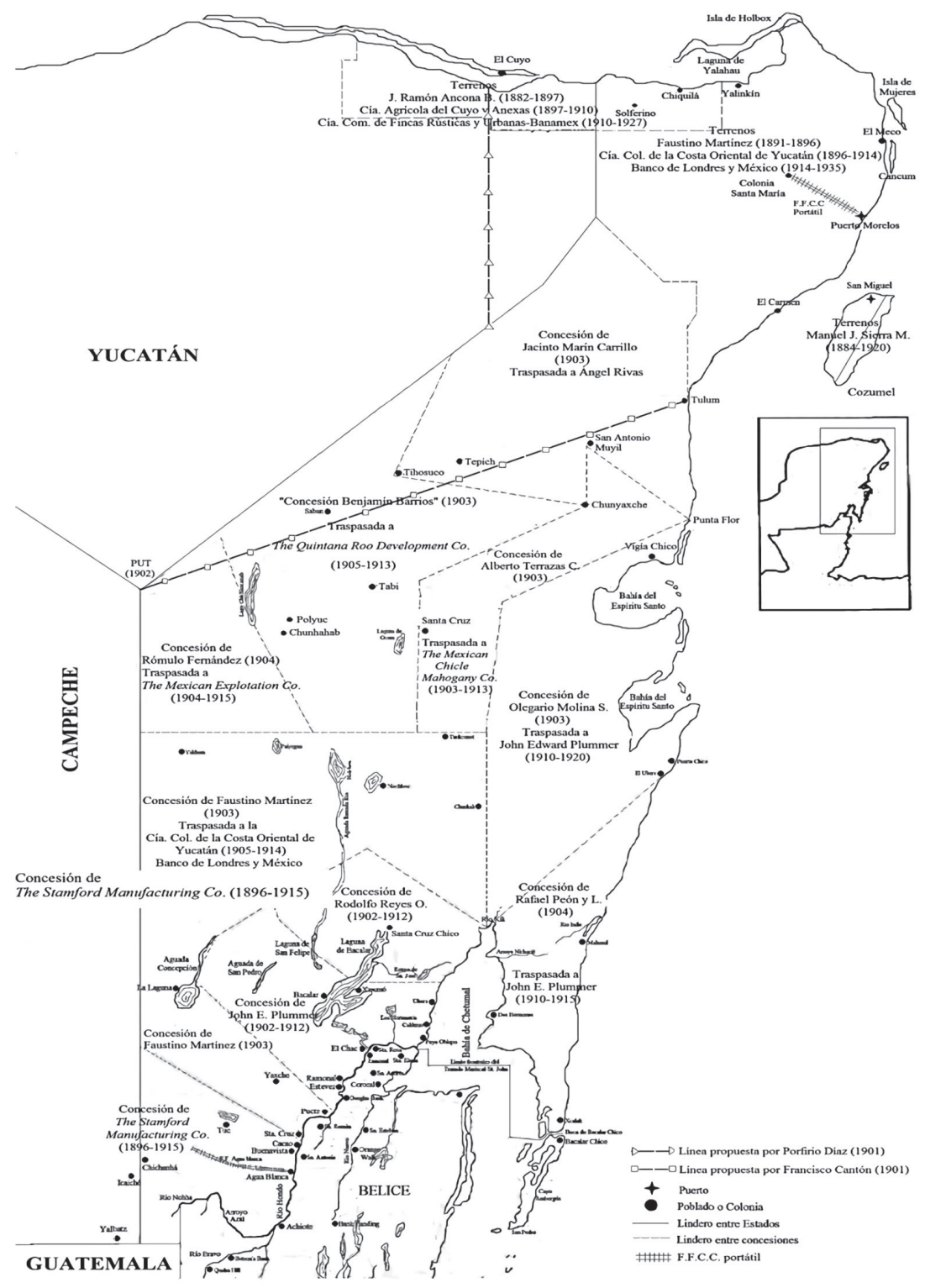

Fuente: elaboración propia con base en Antonio Espinosa (1929). Mapa del Territorio de Quintana Roo. MMOyB. Colección General. Quintana Roo. Varilla CGQROO03. No. Clasificador 7590-CGE-7265-A. 
tidades: Faustino Martínez y Cía. y la Compañía Colonizadora de la Costa Oriental de Yucatán. La titánica empresa comienza con la gestión de concesiones y franquicia de libre importación, la edificación de almacenes en las islas de Holbox, Cozumel y Mujeres, el deslinde de tierras, la creación de un par de asentamientos, el enganche de colonos, acuerdos conjuntos para la explotación forestal, la construcción de infraestructura para comunicar, situar herramientas, mercancías e insumos importados, trasladar la fuerza de trabajo y ganado, llevar a cabo actividades agrícolas y extractivas. Igualmente, conforma la red de gestores, representantes comerciales y legales. Podemos destacar a Rafael Peón y Juan F. Molina Solís en la ciudad de Mérida, quien es facultado para representar a Faustino Martínez y Cía. ante las autoridades administrativas y judiciales yucatecas, y a la casa comercial Rivas Hermanos en el puerto de Progreso para realizar los embarques correspondientes. El empresario inglés John E. Plummer y la casa mercantil The Stevens Brothers \& Co. -propiedad de Ewing Steven, José María Rosado y John Pourie Robertson- que comercializa el palo de tinte en la ciudad-puerto de Belice. José Escandón que figura como agente en Cuba. El comerciante Chas Weylandt en Londres, ${ }^{19}$ quien tiene la potestad de consignar, hipotecar o negociar con las propiedades de Martínez en Gran Bretaña o donde fuere necesario.

Una de las primeras actividades productivas emplazadas por el empresario navarro en los terrenos orientales de Yucatán es la creación de asentamientos que verificasen el cumplimiento de su compromiso para ocupar la zona como la colonia de Nichupté, junto a la laguna del mismo nombre en Cancún, la Vega de San José -Las Vegas o San José de la Vega-, Buenaventura o El Meco. En esta primera instancia, Martínez se asocia con su hermano Juan y con Antonio Suárez, un comerciante español avecindado en Nueva Orleans. ${ }^{20}$ La Vega es una pequeña plantación tabacalera de 23 kilómetros cuadrados, cuyas actividades principales son el cultivo del tabaco, vainilla, caña de azúcar y la extracción de palo de tinte y chicle, punto en el que se construyen una casa principal de estilo europeo, dos bodegas para beneficiar el tabaco en rama y las chozas que albergaron a 110 colonos enganchados en la isla de Cuba por Escandón y chicleros provenientes de Tuxpan, Veracruz. Igualmente lleva a cabo el tendido de

\footnotetext{
${ }^{19}$ Poder especial de los señores Faustino Martínez y Cía. a favor de Juan F. Molina Solís, 20 de septiembre de 1894, ciudad de México, FA, vol. 5, ff. 196-198, AHN; Poder especial de los señores Faustino Martínez y Cía. a favor de Chas Weylandt, 10 de noviembre de 1894, ciudad de México, FA, vol. 5, ff. 324-326, AHN.

${ }^{20}$ Antonio Suárez participó con el terreno de la finca y los recursos para adquirir aperos, enseres y construir las edificaciones necesarias para el cultivo y preparación del tabaco. Por su parte, los hermanos Martínez invirtieron 20000 pesos. Constitución de la sociedad Martínez, Suárez y Cía., 12 de julio de 1894, ciudad de México, FA, vol. 5, ff. 33-38, AHN.
} 
vías de ferrocarril portátiles, la introducción de ganado mular, vacuno y caballar y la construcción del embarcadero denominado El Meco, ubicado entre Isla Mujeres y Cancún, con una extensión de 30 metros, donde las embarcaciones Salvamento, Manuelito y Regalo movilizaron fuerza de trabajo, insumos, ganado, tabaco, tintórea y resina. Con la expansión de las zonas productivas construye un nuevo muelle de 35 kilómetros con mayor capacidad y calado, que se ubica en la zona denominada Quebrado del Corcho o Punta Corchos, posteriormente conocido como Morelos -hoy Puerto Morelos, Quintana Roo- (Rangel, 2014, pp. 317-358). Faustino Martínez y Cía. tiene la capacidad de cultivar, comprar y comercializar el tabaco en rama entre algunas de las principales cigarreras establecidas en el país, propiedad de empresarios iberos como El Modelo y Balsa Hermanos y Cía. La producción tabacalera es importante pues observamos existencias de 11.5 toneladas de hebra con un valor de 2500 pesos. Para 1896 , las construcciones, insumos y bienes de la vega estuvieron valuados en 12102 pesos, de acuerdo con lo señalado por los corredores Emilio Mävers y Segismundo Wolf. ${ }^{21}$

En cuanto al corte de maderas preciosas, palo de tinte, extracción de resina y cocción de chicle, además de las actividades realizadas por cubanos y tuxpeños, Martínez lleva a cabo el arrendamiento de sus bosques para justificar la ocupación del semidespoblado, aprovechar los recursos forestales, frenar los intereses de otros comerciantes y afrontar los problemas por deslindar su propiedad con los terrenos adyacentes al oeste de El Cuyo de Ancona, propiedad de José Ramón Ancona. ${ }^{22}$ Entre 1895 y 1899, el empresario navarro realiza acuerdos de explotación de tintórea y resinas con los navieros-comerciantes españoles Ángel Alberto y Policarpo Rivas del puerto de Progreso, el hacendado yucateco Rafael Peón y el comerciante inglés John E. Plummer. Los hermanos Rivas pagan una renta anual de 15000 pesos para explotar a nombre de Faustino Martínez y Cía. un terreno de catorce kilómetros cuadrados ubicado entre Yalahau y Punta Arena. Además, ambas partes invierten 50000 pesos, Martínez se encarga de la comercialización de la materia prima en el exterior y pone a disposición sus franquicias aduanales y autorizaciones de cabotaje, los Rivas se encargan de todas las operaciones, contratación de fuerza de tra-

${ }^{21}$ Véase a detalle propiedad de Suárez y letra de cambio por 725 pesos que suscribió Faustino Martínez con los hermanos Balsa, en Modificación de la sociedad Faustino Martínez y Cía., 4 de septiembre de 1895, ciudad de México, Fondo Antiguo, vol. 8, ff. 131-141, AHN; Letra de cambio por $\$ 725.00$ a favor de Israel Ramos Martínez, 13 de julio de 1895, ciudad de México, Fondo Antiguo, vol. 5, ff. 39-41, AHN.

${ }^{22}$ José Ramón Ancona es el segundo propietario de la zona con un terreno de 2000 kilómetros cuadrados, El Cuyo de Ancona y Anexas, en donde realiza cortes furtivos en las posesiones de Martínez (Rangel, 2014, p. 270). 
bajo para el corte de la tintórea y la extracción de resina de chicozapote, misma que requiere la movilización de 1000 jornaleros en cada temporada. Igualmente, colocan vías férreas portátiles y construyen embarcaderos, tongaderos, aserraderos, monterías y asentamientos, como fue el caso de Yalinkín, frente a la isla de Holbox, en donde se tendieron 53 kilómetros de vía decauville, contaron también con las embarcaciones y realizan el cabotaje entre Yalahau y los puertos de Progreso y Veracruz. ${ }^{23}$ En promedio, cada año se extraen alrededor de 5000 toneladas de chicle con valor de 25000 pesos.

Otro acuerdo para el usufructo de recursos forestales lo realizó el comerciante navarro con el hacendado yucateco Rafael Peón, quien se obliga a pagar 56000 pesos de renta por un bosque de catorce kilómetros cuadrados adyacente al explotado por los hermanos Rivas y con similares condiciones para el usufructo de la concesión. ${ }^{24}$ La explotación anual media de Peón es de 4000 toneladas con valor de 20000 pesos. El tercer socio es el comerciante inglés J. E. Plummer, establecido en la ciudad-puerto de Belice, quien previamente se caracteriza por ser un contrabandista de maderas en la costa oriental de Yucatán, concesionario del gobierno porfiriano y socio del campechano Manuel J. Sierra (Rangel, 2014, pp. 172-184). Plumer y Martínez acordaron el arriendo de un terreno durante cinco años por la suma de 500000 pesos, lamentablemente, la documentación consultada no arroja información sobre las cantidades de palo de tinte o chicle extraídos ${ }^{25}$ pero este contrato le genera ganancias por un monto mínimo de 73609 pesos anuales más la parte proporcional por la exportación de chicle. Entre 1895 y 1899, de los terrenos de Faustino Martínez se exportan por el puerto de Progreso casi 28500 toneladas de palo de tinte y alrededor de 83 toneladas de chicle con un valor de 219123 pesos y 39704 pesos, respectivamente (véase cuadro 1). El principal competidor del comerciante navarro es Ramón Ancona, quien para las mismas temporadas exportaba más de 15000 toneladas de tintórea y dos toneladas de chicle. ${ }^{26}$

En cuanto a las actividades extractivas que realizaba Martínez en la concesión de Río Hondo, cuya base fue el Campamento Xcopen, y otros asentamientos conocidos como Reforma y Naranjal, un conjunto de cobertizos de guano mayormente comunicados por una vía portátil y una

\footnotetext{
${ }^{23}$ Contrato de arrendamiento de Faustino Martínez y Cía. a favor de Rivas Hermanos, 30 de octubre de 1894, ciudad de México, FA, vol. 5, ff. 307-313, AHN; Asociación en participación entre los señores Faustino Martínez y Cía. y los señores Rivas Hermanos, 16 de agosto de 1895, ciudad de México, FA, vol. 8, ff. 89-94, AHN. Acta constitutiva de la Compañía Colonizadora de la Costa Oriental de Yucatán, S. A., 2 de marzo de 1896, ciudad de México, FA, vol. 21, ff. 315-318, AHN.

${ }^{24}$ Acta constitutiva [...], FA, vol. 21, ff. 315-318, AHN.

${ }^{25}$ Acta constitutiva [...], FA, vol. 21, ff. 315-318, AHN.

${ }^{26}$ Boletín de Estadística del Estado de Yucatán, 1895-1899.
} 
Am. Lat. Hist. Econ., año 25, núm. 3, septiembre-diciembre, 2018, pp. 160-186

\section{CUADRO 1. EXPORTACIONES POR EL PUERTO DE PROGRESO DE LOS ARRENDATARIOS DE FAUSTINO MARTÍNEZ (1895-1899)}

\begin{tabular}{|c|c|c|c|c|c|}
\hline \multirow[t]{2}{*}{ Año } & \multirow[t]{2}{*}{ Empresario } & \multicolumn{2}{|c|}{ Palo de tinte } & \multicolumn{2}{|c|}{ Chicle } \\
\hline & & $\begin{array}{l}\text { Peso } \\
(\mathrm{kg})\end{array}$ & $\begin{array}{l}\text { Valor } \\
\text { (pesos) }\end{array}$ & $\begin{array}{l}\text { Peso } \\
(\mathrm{kg})\end{array}$ & $\begin{array}{l}\text { Valor } \\
\text { (pesos) }\end{array}$ \\
\hline 1895 & $\begin{array}{l}\text { Faustino Martínez } \\
\text { Faustino Martínez }\end{array}$ & $\begin{array}{l}3522985 \\
4738897\end{array}$ & $\begin{array}{r}\text { s. d. } \\
95880.95\end{array}$ & $\begin{array}{r}\text { s. d. } \\
64269\end{array}$ & $\begin{array}{r}\text { s. d. } \\
31674\end{array}$ \\
\hline 1896 & Rafael Peón & $\begin{array}{r}15719778 \\
\text { s. d. }\end{array}$ & s. d. & 18684 & 8120 \\
\hline 1897 & $\begin{array}{l}\text { Rafael Peón } \\
\text { Rivas Hermanos }\end{array}$ & $\begin{array}{r}1966195 \\
1151741\end{array}$ & $\begin{array}{r}47200 \\
25172.52\end{array}$ & s. d. & s. d. \\
\hline 1898 & $\begin{array}{l}\text { Rafael Peón } \\
\text { Rivas Hermanos }\end{array}$ & $\begin{array}{r}426411 \\
\text { s. d. }\end{array}$ & $\begin{array}{r}12000 \\
\text { s. d. }\end{array}$ & $\begin{array}{l}\text { s. d. } \\
\text { s. d. }\end{array}$ & $\begin{array}{l}\text { s. d. } \\
\text { s. d. }\end{array}$ \\
\hline 1899 & $\begin{array}{l}\text { Rafael Peón } \\
\text { Rivas Hermanos }\end{array}$ & $\begin{array}{r}969158 \\
4600\end{array}$ & $\begin{array}{r}38766.33 \\
103.66\end{array}$ & $\begin{array}{l}\text { s. d. } \\
\text { s. d. }\end{array}$ & $\begin{array}{l}\text { s. d. } \\
\text { s. d. }\end{array}$ \\
\hline Total & & 28499765 & 219123.46 & 82953 & 39794 \\
\hline
\end{tabular}

Fuente: elaboración propia con base en Boletín de Estadística del Estado de Yucatán (1895-1899).

línea telefónica de aproximadamente 85 kilómetros donde se utilizaban entre 600 y 700 mulas para el arrastre de los carros que trasladaron productos explotados y las mercancías requeridas para las actividades forestales realizadas en una zona de 30 kilómetros cuadrados de bosque. Las maderas y resinas que se producían en estos campamentos fueron enviadas principalmente a Payo Obispo (hoy Chtumal). En estos asentamientos se ocupa anualmente una fuerza de trabajo de alrededor de 1000 chicleros tuxpeños, enganches realizados por los contratistas Alejandro Chao y Librado García en Veracruz. También se requiere de la movilización de ganado mular para el arrastre de los carros que trasladan productos explotados, las mercancías requeridas y trabajadores, por lo que son llevadas desde Progreso entre 600 y 700 cabezas. La producción anual se estima en alrededor de 18000 toneladas de resina preparada con valor de 43 000 pesos, exportadas por el circuito comercial Payo Obispo-Belice-Nueva York (Rangel, 2014, pp. 325-326; Secretaría de Fomento, 1913, pp. 577, 581). Además, en estas actividades se pone en evidencia la extracción y la comercialización fraudulenta de chicle, pues en al menos una ocasión, los representantes de Martínez no realizan el pago del total de los derechos de explotación y exportación en el puerto de Progreso ya que de 45300 pesos que debían cubrir por la salida de 750 toneladas de goma, solamente 
pagan la suma de 31800 pesos que amparan solamente 600 toneladas de chicle. ${ }^{27}$ A finales de 1895, Faustino Martínez y Cía. representa un negocio valorado en 1700000 pesos, en sus almacenes cuenta con existencias de más de once toneladas de hoja de tabaco con valor de 2500 pesos, alrededor de 60 toneladas de chicle preparado por un importe de 46000 pesos y más de 500 toneladas de palo de tinte con un costo en el mercado de 10 000 pesos (Rangel, 2014, pp. 317-358).

\section{Faustino Martínez y la COMPañía COlONizAdora de la Costa Oriental de Yucatán (1896-1909)}

Es en la segunda mitad de la década de 1890 que se presenta el pináculo de los negocios del empresario navarro al participar en una serie de sociedades mercantiles que representa el auge de la economía porfiriana como la Compañía Colonizadora de la Costa Oriental de Yucatán, el Banco de Londres y México, la Compañía Agrícola del Xico, la Compañía del Ferrocarril de Xico y San Rafael y la Compañía de los Ferrocarriles Sud-Orientales en Yucatán. Es la Compañía Colonizadora una empresa agrícola-forestal con la que aprovecha y usufructúa terrenos y bosques en la costa oriental de la península yucateca y en el territorio federal de Quintana Roo. Este negocio nos permite observar la sinergia entre Faustino Martínez, el empresariado y la clase política porfiriana para conformar las modernas empresas financiadas a través de un selecto grupo de accionistas que controlan consejos directivos y administrativos del conglomerado de compañías que dan forma y fondo a la economía del México decimonónico que transita al siguiente siglo y se muestra inmerso en el desarrollo capitalista de la época. Un contexto favorable debido al aumento en la demanda de materias primas en el mercado internacional, lo que incentiva la participación del empresariado, como Martínez lo lleva a cabo, beneficiándose del incremento en la demanda de los productos de agroexportación como el chicle y las maderas preciosas, aumentando las actividades extractivas por medio de sus negociaciones en el oriente yucateco, fenómeno que atrae intereses de destacados miembros de la oligarquía económica avecindada en la ciudad de México. En ese sentido, los negocios del empresario navarro transitan de los acuerdos y operacio-

${ }^{27}$ En agosto de 1905 Fermín O. López, vecino de Mérida, comunica a las secretarías de Hacienda y Fomento el escandaloso fraude cometido al fisco por parte de los trabajadores de Martínez. Fermín O. López informa a los Secretarios de Hacienda y de Fomento sobre el fraude al fisco que se está cometiendo en Río Hondo, Quintana Roo, encabezado por el señor Faustino Martínez, 21 de agosto de 1905, ciudad de México, Fondo Limantour, carp. 22, leg. 120, 3 ff., Archivo del Centro de Estudios de Historia de México (ACEHM). 
nes de explotación forestal con socios regionales a la constitución de una empresa agrícola-explotadora-colonizadora-mercantil de mayor escala, una multidimensional sociedad anónima que participa de la economía de explotación-exportación y satisface la necesidad de recursos madereros en mercados internacionales como Belice, La Habana, Nueva Orleans, Nueva York, Liverpool, Fráncfort, Hamburgo, El Havre, entre otros.

El 2 de marzo de 1896 la Compañía Colonizadora de la Costa Oriental de Yucatán se conforma y establece su domicilio en el número 2 de la calle de Lerdo -calle de Palma-, en el centro financiero y comercial de la ciudad de México. Su objetivo principal es adquirir y aprovechar los terrenos de Faustino Martínez, por ende, continuar con actividades como el deslinde, el poblamiento y la explotación de recursos forestales. ${ }^{28}$ Con un capital inicial de 2000000 de pesos dividido en 20000 acciones y con la necesidad de contar con mayor inversión, la naciente sociedad está en condiciones de cotizar en la Bolsa de México, siendo Segismundo Wolf el corredor designado por Martínez para promoverla. Es importante señalar dicha incursión en el naciente mundo bursátil mexicano ya que de 100 pesos que cuestan las acciones, durante los siguientes dos años valen entre $115 \mathrm{y}$ 120 pesos. Además, la sociedad del empresario navarro se encuentra junto con otras importantes sociedades como la Compañía de Cigarros El Buen Tono, la Fábrica de Papel de San Rafael, la Compañía de Tejidos San Antonio y Anexas Barrón, la Colmena y Miraflores, la Fábrica de Tejidos San Ildefonso o la Compañía Industrial de Orizaba, cuyos documentos nominativos oscilaban entre los 100 y los 275 pesos. ${ }^{29}$

La novedosa y multifacética empresa de Martínez, de la que es socio mayoritario y gerente por nueve años (1896-1905), le permite ensanchar intereses con sus socios y amigos con los que conforma el consejo de administración. Empresarios, propietarios-terratenientes, políticos y capitalistas nacionales y extranjeros avecindados en la ciudad de México como Manuel González, quien ocupa la presidencia (1896-1901), Henry C. Watters, que funge como vicepresidente (1896-1910), Juan B. Martínez como comisario propietario e Íñigo Noriega como comisario suplente (1896-1900), Ignacio de la Torre, vocal e Indalecio Ibáñez, secretario (1896-1905), cada cual con una participación en el capital inicial (véase cuadro 2). ${ }^{30}$ Igualmente, encontramos diversos nombres de empresarios consentidos del porfiriato que ocupan la presidencia, como Thomas Braniff Woods (1901-1905) y José Sánchez Ramos (1905-1910), que sustituyen en la dirección a Martínez, como Ruperto Crespo (1905-1906) y Ángel

\footnotetext{
${ }^{28}$ Acta constitutiva [...], FA, vol. 2, f. 334, AHN.

${ }^{29}$ El Tiempo, 24 de mayo de 1896, p. 3.

${ }^{30}$ Acta constitutiva [...], FA, vol. 21, f. 322, AHN.
} 
Rodrigo Fernández (1906-1908), o se convierten en representantes legales como Alphonse Mitchell. Así como también una serie de consejeros de la talla de Tomás Braniff Ricard, Adolfo Prieto, Indalecio Sánchez Gavito, León Signoret, Enrique Tron, Arturo Hube, Guillermo Hopfner, Philip Robertson, William B. Mitchell, Pablo Macedo, Francisco Garza, Aurelio Díaz, A. Sánchez Juárez, entre otros (Rangel, 2014, pp. 361-366).

Durante la dirección de Faustino Martínez, la Compañía Colonizadora puede considerarse, en el marco de la revolución gerencial, una empresa moderna por los elementos que la integran y los resultados satisfactorios para los accionistas. El empresario navarro lleva a cabo una serie de estrategias para incrementar la productividad de la negociación como la contratación de un crédito con el Banco de Londres y México por 700000 pesos, recapitalización para adquirir varios buques de vapor, como el Ibero y el Olimpia, de poco calado con capacidad de 300 toneladas, el remolcador Yucatán que se incorporaban a la flotilla existente con las pequeñas embarcaciones Salvamento, Manuelita y Regalo, mismos que mejoran el servicio de cabotaje entre la costa oriental de Yucatán y los puertos de altura de Progreso y Veracruz. En cuanto a la infraestructura existente, realiza mejoras a la colonia Nichupté, la Vega de San José y el Puerto de Morelos, crea nuevos puntos de almacenamiento y asentamientos enclavados en la selva como la colonia Santa María -Leona Vicario-, un embarcadero denominado El Carmen -Playa del Carmen-, entre otros, ocupados de manera temporal por la fuerza de trabajo requerida para las actividades extractivas, misma que se incrementa a través de los enganches realizados por los viejos conocidos de Martínez, los contratistas José Escandón en La Habana, Alejandro Chao y Librado García en Tuxpan. A fines del siglo XIX en los terrenos del empresario navarro se encuentran entre 600 y 1500 jornaleros provenientes de Belice, Corea, Cuba, Puerto Rico, así como también de Tuxpan y otros puntos de la república mexicana, mismos que integran casi la mitad de la población establecida en la costa oriental de Yucatán. Para 1903, las autoridades del territorio federal de Quintana Roo informan la presencia de 1258 trabajadores eventuales y más de 500 habitantes fijos de una población estimada en 4000 habitantes. ${ }^{31}$ Con ello se solventan de manera mínima los compromisos de colonización adquiridos por el empresario navarro con el gobierno federal.

$\mathrm{Al}$ igual que con Faustino Martínez y Cía., las principales actividades productivas de la Compañía Colonizadora son la explotación y la exportación de palo de tinte y chicle a los mercados estadunidense y europeo,

\footnotetext{
${ }^{31}$ Informe administrativo rendido a la Secretaría de Gobernación, por el Jefe Político del Territorio de Quintana Roo, Gral. José M. de la Vega., Campamento Vega, 30 de noviembre de 1903, Fondo Gobernación, caja 767, exp. 1, f. 10v, AGN.
} 
Am. Lat. Hist. Econ., año 25, núm. 3, septiembre-diciembre, 2018, pp. 160-186

CUADRO 2. ACCIONISTAS INICIALES DE LA COMPAÑÍA COLONIZADORA DE LA COSTA ORIENTAL DE YUCATÁN (1896)

\begin{tabular}{lrrr}
\hline Socio & Acciones & Valor (pesos) & Porcentaje \\
& & & \\
Faustino Martínez $^{\mathrm{a}}$ & 15750 & 1575000 & 78.75 \\
Juan Bautista Martínez $^{\mathrm{a}}$ & 1750 & 175000 & 8.75 \\
Henry Campbell Watters $_{\text {Ignacio de la Torre }}$ & 650 & 65000 & 3.25 \\
Manuel González Cosío & 600 & 60000 & 3 \\
Indalecio Ibáñez & 600 & 60000 & 3 \\
Iñigo Noriega Lasso & 600 & 60000 & 3 \\
Total & 50 & 5000 & 0.25 \\
\hline
\end{tabular}

${ }^{\text {a }}$ Socio de la Faustino Martínez y Cía.

Fuente: elaboración propia con base en Acta constitutiva de la Compañía Colonizadora de la Costa Oriental de Yucatán, S. A., 2 de marzo de 1896, Ciudad de México, FA, vol. 21, f. 322, AHN.

negocio que representa varios millones de pesos en ganancia para la empresa, que en su primer año de actividades se considera una de las más ricas de la república mexicana, testimonio del sorprendente progreso y del desarrollo capitalista del país. La tintórea exportada anualmente a la ciudad-puerto de Belice representa 6000 toneladas con un precio por arriba de los 132000 pesos..$^{32}$ Durante la gerencia del empresario español, las exportaciones por el puerto de Progreso eran de 113406 toneladas de palo de tinte con valor de 621148 pesos y 3655 toneladas de resina con un precio de 1408213 pesos, respectivamente (véase cuadro 3). Los principales destinos fueron los puertos ingleses de Chester, Falmouth, Goole, Liverpool y Manchester, San Petersburgo y Windaw en Rusia, el puerto alemán de Hamburgo, Génova en Italia y Nueva York en Estados Unidos. Entre los años de 1905 y 1906 no podemos vislumbrar lo acontecido con las actividades de la sociedad forestal debido a la falta de documentación. Además, para estas fechas Faustino Martínez solamente forma parte del consejo de administración de la sociedad. Igualmente debemos señalar que hasta el momento no hemos localizado la información relativa a las cantidades embarcadas y exportadas por la isla de Cozumel y Payo Obispo. Pero por las cantidades presentadas, la Compañía Colonizadora es un

${ }^{32}$ Nuestras grandes empresas: La Compañía Colonizadora de la Costa Oriental de Yucatán, La Revista de Mérida, 8 de octubre de 1898, p. 1. 
CUADRO 3. EXPORTACIONES POR EL PUERTO DE PROGRESO, YUCATÁN, DE LA COMPAÑÍA COLONIZADORA DE LA COSTA ORIENTAL DE YUCATÁN (1896-1910)

\begin{tabular}{|c|c|c|c|c|}
\hline \multirow[t]{2}{*}{ Año } & \multicolumn{2}{|c|}{ Palo de tinte } & \multicolumn{2}{|c|}{ Chicle } \\
\hline & Peso (kg) & Valor (pesos) & Peso (kg) & Valor (pesos) \\
\hline 1896 & 0 & 0 & 152727 & 76334 \\
\hline 1897 & 4536333 & 294954 & 255712 & 5350 \\
\hline 1898 & 163776 & 82274 & 1445233 & 36590 \\
\hline 1899 & 832553 & 31460 & 590096 & 418638 \\
\hline 1902 & 980108 & 39167 & s. d. & s. d. \\
\hline $1903^{\mathrm{a}}$ & 1477267 & 44318 & 253227 & 190711 \\
\hline 1904 & 3350639 & 128975 & 689503 & 484335 \\
\hline 1905 & 0 & 0 & 268183 & 196254 \\
\hline 1906 & 3073651 & 52568 & 427149 & 358502 \\
\hline 1907 & 864730 & 10810 & 116950 & 98500 \\
\hline 1908 & 734596 & 735 & 196065 & 140264 \\
\hline 1909 & 0 & 0 & 0 & 0 \\
\hline 1910 & 466802 & 9336 & 0 & 0 \\
\hline Total & 11340676 & 621148 & 3654681 & 1408213 \\
\hline
\end{tabular}

${ }^{\text {a }}$ Datos de los meses de octubre a diciembre de 1903.

Fuente: elaboración propia con base en Boletín de Estadística del Estado de Yucatán (1896-1910).

negocio productivo durante la primera década que explota las concesiones otorgadas por la autoridad porfiriana.

Después de una década el dueño de los bosques de la costa oriental de Yucatán enfrenta la precaria situación del mercado internacional, pues el verano de 1905 se manifiesta como un periodo crítico, de transformaciones y afianzamiento de intereses para los accionistas de la sociedad forestal. Las estrategias y acuerdos tomados por el empresario navarro no se adaptan a las adversidades del mercado internacional y Martínez se ve obligado a tomar su última decisión gerencial, ceder la dirección de la empresa a Ruperto Crespo y traspasar los derechos de explotación y franquicias fiscales dentro de los más de 14000 kilómetros cuadrados que conforman sus propiedades y la concesión de Río Hondo en territorio quintanarroense, al consejo de administración de la Compañía Coloniza- 
dora ${ }^{33}$ Pero conserva los títulos de propiedad que amparan más de 4800 kilómetros cuadrados de los terrenos deslindados, sus 15000 acciones y su posición en el órgano consultivo de la negociación al ser el capitalista mayoritario. Igualmente se separa de las juntas directivas de las demás sociedades de las que es partícipe, como el Banco de Londres y México o la Compañía Agrícola del Xico, conserva solamente los documentos nominativos y nombra a la institución financiera como su apoderada. Podemos observar que la decisión de Faustino Martínez de separarse de manera precipitada de la administración directa de sus negocios e intereses responde a cuestiones de salud y a su visión empresarial, pues la economía del país comenzaba a presentar los síntomas de la crisis que acontecería un par de años más tarde. Además, la Compañía Colonizadora transita por una precaria situación financiera al no cumplir con sus compromisos crediticios con el banco londinense, se hace efectivo el pagaré por más de 700000 pesos y la institución bancaria se encarga de la dirección y pasivos de la empresa. ${ }^{34}$ En junio de 1909 acontece la muerte del empresario navarro dueño de los bosques de la costa oriental de Yucatán, con ello el Banco de Londres, como su apoderado, se ocupa de todos sus intereses y negocios en el territorio de Quintana Roo y queda en posesión de la Compañía Colonizadora, comenzando una nueva era en los negocios de la extracción forestal en la región que corre a cargo de empresas extranjeras que durará hasta el advenimiento de la revolución en la década siguiente.

\section{CONCLUSiOnes}

Durante las tres décadas que Faustino Martínez lleva a cabo sus negocios se presenta una serie de cambios estructurales en la economía mexicana del último tercio del siglo XIX, así como también la crisis que caracteriza la primera década del siglo pasado. En este contexto, el empresario navarro adecua sus relaciones, intereses, inversiones y decisiones gerenciales que le permiten convertirse en el dueño de los bosques de la costa oriental de Yucatán y dirigir la economía de exportación de materias primas para satisfacer el mercado internacional. Es por ello que este personaje debe ocupar un lugar más trascendente en la historiografía económica de México, pues forma parte de la nómina de actores que construyen la economía

${ }^{33}$ Cesión y traspaso del señor don Faustino Martínez a favor de la Compañía Colonizadora de la Costa Oriental de Yucatán, 27 de julio de 1905, ciudad de México, Fondo Contemporáneo, ff. 158-169, AHN.

${ }^{34}$ Dación de pago de la Compañía Colonizadora de la Costa Oriental de Yucatán, S. A. a favor del Banco de Londres y México, S. A., 1 de marzo de 1910, ciudad de México, Fondo Contemporáneo, vol. 70, ff. 47-62, AHN. 
del país en uno de los periodos más representativos de la historia nacional. Aprovecha su participación en el desarrollo capitalista de la época porfiriana para constituirse como un destacado empresario, un importante inversionista y como un personaje con fuerte influencia dentro del empresariado establecido en México. Su participación en los principales negocios, como dimos cuenta, le permite departir, tomar decisiones e imponer sus estrategias empresariales ante personajes como Iñigo Noriega o Thomas Braniff, arquetipos del grupo en el poder durante el porfiriato. Conforma el estrecho grupo de hombres de negocios que, desde la ciudad de México, constituyen sociedades mercantiles, financieras, agrícolas, de transporte o de explotación de recursos naturales que aprovechan la riqueza del vasto territorio nacional. Estos actores económicos propician la acumulación de capital, la concentración de los medios de producción y se enriquecen de manera vertiginosa, aprovechan las oportunidades de negocio que el régimen porfiriano les brinda, son el motor del progreso del México de finales del siglo XIX, como lo demuestra la intervención de Martínez en sociedades como la Compañía Colonizadora de la Costa Oriental de Yucatán, el Banco de Londres y México o la Compañía Agrícola del Xico.

La presencia del empresario navarro en la región de frontera forestal del oriente de la península yucateca le permite desarrollar su afán de lucro y beneficiarse de los vastos terrenos y ricos bosques para establecer una las más importantes negociaciones de colonización, de actividades agrícolas y de extracción de recursos maderables, un sector económico involucrado en la sinergia de los países desarrollados y los periféricos. Podemos señalar que conforma la economía de enclave bajo el control de capital externo centrado en actividades de explotación de materias primas en el sureste mexicano. De igual manera, Martínez forma parte de los marcadores económicos de soberanía necesarios en esta región de frontera forestal al establecer la infraestructura y asentamientos que coadyuvan al proceso de ocupación, al control territorial realizado por el gobierno federal, a la firma del Tratado Mariscal-St. John (1893-1898), al proyecto porfiriano de creación del territorio federal de Quintana Roo (1903) y la imposición de la economía de extracción-exportación de recursos maderables que caracteriza a la zona hasta mediados del siglo pasado. Se trata entonces de un empresario que hace uso de estrategias acordes a la época, se beneficia de las concesiones otorgadas por el gobierno federal, coadyuva con el proyecto de la autoridad para promover el desarrollo capitalista y el progreso económico del país, utiliza el enganche y la explotación de fuerza de trabajo, llega a cometer fraude fiscal y favorece a instituciones financieras. Una historia repetida con el curso de los años, sobre todo en momentos de crisis económica. 
Am. Lat. Hist. Econ., año 25, núm. 3, septiembre-diciembre, 2018, pp. 160-186

\section{LISTA DE REFERENCIAS}

Arias, M. (1999). Un empresario español en México: Delfín Sánchez Ramos (18641898). En G. Altamirano (coord.), En la cima del poder. Elites mexicanas, 1830-1930 (pp. 54-101). México: Instituto de Investigaciones Dr. José María Luis Mora.

BARCELÓ, R. (1982). La oligarquía henequenera. Un estudio de caso: Los Escalante (Tesis de licenciatura). Escuela Nacional de Antropología e Historia, México.

Banca Serfin, SNC (1990). 125 años de la Banca Serfin. México: Todo Color.

Banco de Londres y MéXICO (1964). 100 años de banca en México. Primer centenario del Banco de Londres y México, S. A. Institución de depósito, fiduciaria y de ahorro. 18641964. México: Cía. Impresora y Litográfica Juventud.

CARdoso, C. (1978). Presentación. En C. CARdoso (coord.), Formación y desarrollo de la burguesía en el siglo XIX (pp. 12-24). México: Siglo XXI.

Careaga, L., (1990a). Quintana Roo. Textos de su historia t. I. México: Instituto de Investigaciones Dr. José María Luis Mora.

Careaga, L., (1990b). Quintana Roo una historia compartida. México: Instituto de Investigaciones Dr. José María Luis Mora.

CÉSAR, A. y ARnaiz, S. (1983). Estudios socioeconómicos preliminares de Quintana Roo: Sector agropecuario y forestal (1902-1980). Puerto Morelos: Centro de Investigación de Quintana Roo.

CÉSAR, A. y ARnAIZ, S. (1984). Estudios socioeconómicos preliminares de Quintana Roo: el territorio y la población (1902-1983). Puerto Morelos: Centro de Investigaciones de Quintana Roo.

CÉSAR, A. y Arnaiz, S. (1990). Quintana Roo. Sociedad, economía, política, cultura. México: Universidad Nacional Autónoma de México.

Collado, M. (1987). La burguesía mexicana. El emporio Braniff y su participación política 1865-1920. México: Siglo XXI.

Editorial Porrúa (1986). Diccionario Porrúa. Historia, biografía y geografía de México t. III. México: Autor.

Ferrer, M. y Rodríguez, L. (2011). Canarios de Yucatán. Mérida: Universidad Autónoma de Yucatán.

GARCÍA, A. (1986). Los tiempos de Yucatán. Los hombres, las mujeres y la naturaleza (s. XIX). México: Claves Latinoamericanas.

González, L. (2010). Alba y ocaso del porfiriato. México: Fondo de Cultura Económica.

Guerra, F.-X., (2012). México: del antiguo régimen a la revolución (t. I). México: Fondo de Cultura Económica.

Herrero, C. (2004). Los empresarios mexicanos de origen vasco y el desarrollo del capitalismo en México. 1880-1950. México: Universidad Autónoma de México/Plaza y Valdés.

Higuera, A. (1997). Quintana Roo entre tiempos. Política, poblamiento y explotación forestal, 1872-1925. México: Universidad de Quintana Roo/Instituto Quintanarroense de la Cultura. 
LIDA, C. (coord.) (1981). Tres aspectos de la presencia española en México durante el porfiriato: relaciones económicas, comerciantes y población. México: El Colegio de México.

Macías, C. (1997). Nueva frontera mexicana. Milicia, burocracia y ocupación territorial en Quintana Roo. México: Universidad de Quintana Roo.

MACÍAS, G. (2002). La península fracturada. Conformación marítima, social y forestal del territorio federal de Quintana Roo. 1884-1902. México: Centro de Investigaciones y Estudios Superiores en Antropología Social /Porrúa/Universidad de Quintana Roo.

Menéndez, C. (1937). Noventa años de historia de Yucatán (1821-1919). Mérida: Compañía Tipográfica Yucateca.

Nelken-Terner, A. (1997). Frontera rígida, frontera móvil: la normatividad de los límites y algunos aspectos de las soberanías. Revista Mexicana del Caribe, 4, 148-166. DOI: $10.22403 /$ uqroomx/rmc04/06

Pérez, M. (2002). Historia de una elección: la candidatura de Olegario Molina en 1901. México: Universidad Autónoma de Yucatán.

PÉrez, P. (1981). Algunas hipótesis de trabajo sobre la inmigración española a México: los comerciantes. En C. LIDA, Tres aspectos de la presencia española en México durante el porfiriato (pp. 101-173). México: El Colegio de México.

Pérez, M. y SAVARino, F. (2001). El cultivo de las elites: grupos económicos y políticos en Yucatán en los siglos XIX y XX. México: Consejo Nacional para la Cultura y las Artes.

PÉREZ-RAYÓn, N. (1995). Entre la tradición señorial y la modernidad: la familia Escandón Barrón y Escandón Arango. Formación y desarrollo de la burguesía en México durante el porfirismo (1890-1910). México: Universidad Autónoma Metropolitana.

Ramayo, T. (2014). Política, economía chiclera y territorio: Quintana Roo 1917-1940. Mérida: Universidad Autónoma de Yucatán.

RANGEL, E. (2014). Compañias deslindadoras y sociedades forestales. Empresariado en el entorno fronterizo de la costa oriental y creación de un borde en las márgenes del Río Hondo, 1876-1935 (Tesis de doctorado). Centro de Investigaciones y Estudios Superiores en Antropología Social, México.

RoAzen-PARrillo, D. (1990). Las elites de México durante el siglo diecinueve en una economía regional: el ascenso de la familia Olegario Molina Solís en Yucatán hasta 1902. En O. BAÑos (ed.), Sociedad, estructura agraria y estado en Yucatán (pp. 257-279). Mérida: Universidad Autónoma de Yucatán.

Rosado, L. (1940). Un pueblo y un hombre. México: Norte Sur.

Secretaría de Fomento, Colonización e Industria (1913). Memoria de Fomento (1911-1913). México: Imprenta y Fototipia de la Secretaría de Fomento.

Secretaría de Hacienda y Crédito Público (1891). Memoria de Hacienda y Crédito Público correspondiente al año económico de 1888 a 1889 presentada por el Secretario del ramo Lic. Manuel Dublán al Congreso de la Unión. México: Autor/Imp. de I. Escalante.

SuÁREZ, V. (1977). La evolución económica de Yucatán a través del siglo XIX (tt. I-II). Mérida: Universidad de Yucatán. 
Am. Lat. Hist. Econ., año 25, núm. 3, septiembre-diciembre, 2018, pp. 160-186

Trujillo, M. (1997). La fábrica La Magdalena Contreras: una empresa textil precursora en el valle de México. En C. Marichal y M. Cerruti (comps.), Historia de las grandes empresas en México 1850-1939 (pp. 245-274). México: Fondo de Cultura Económica/Universidad Autónoma de Nuevo León.

Trujillo, M. (2000). Empresariado y manufactura textil en la ciudad de México y su periferia: siglo XIX (2000). México: Centro de Investigaciones y Estudios Superiores en Antropología Social.

Trujillo, M. (2001). El empresario textil de la ciudad de México y sus alrededores, 1880-1910. En C. Agostoni y E. Speckman, Modernidad, tradición y alteridad. La ciudad de México en el cambio de siglo (XIX-XX) (pp. 33-48). México: Universidad Nacional Autónoma de México.

Trujillo, M. y Contreras, J. (coords.) (2003). Formación empresarial, fomento industrial y compañías agrícolas en el México del silgo XIX. México: Centro de Investigaciones y Estudios Superiores en Antropología Social.

VALERIO, S. (2003). Empresarios españoles en Guadalajara durante el porfiriato. La casa Fernández del Valle. En M. Trujillo y J. ConTreras (coords.), Formación empresarial, fomento industrial y compañías agrícolas en el México del silgo XIX (pp. 50-66). México: Centro de Investigaciones y Estudios Superiores en Antropología Social.

Villalobos, M. (2006). Bosque sitiado. Asaltos armados, concesiones forestales y estrategias de resistencia durante la Guerra de Castas. México: Centro de Investigaciones y Estudios Superiores en Antropología Social/Instituto Nacional de Antropología e Historia/ Miguel Ángel Porrúa.

Zertuche, F. (1992). Las islas del Caribe mexicano. En M. Reyes (coord.), Cartografía histórica de las islas mexicanas (pp. 19-38). México: Secretaría de Gobernación.

\section{OTRAS FUENTES}

\section{Hemerografía}

Boletín de Estadística del Estado de Yucatán, años 1895-1910, Mérida, Yucatán, México.

El Correo Español, ciudad de México, México.

El Monitor Republicano, ciudad de México, México.

El Imparcial, ciudad de México, México.

El Popular, ciudad de México, México.

El Tiempo, ciudad de México, México.

La Revista de Mérida, Mérida, Yucatán, México.

Le Trait d'Unión, ciudad de México, México.

The Mexican Herald, ciudad de México, México.

The Two Republics, ciudad de México, México. 


\section{Archivos}

ACenm Archivo del Centro de Estudios de Historia de México, Ciudad de México, México.

AGN Archivo General de la Nación, Ciudad de México, México.

AHGE Archivo Histórico Genaro Estrada, Acervo Histórico Diplomático, Secretaría de Relaciones Exteriores, Ciudad de México, México.

AHN Archivo Histórico del Archivo General de Notarías, Ciudad de México, México.

ммов Mapoteca Manuel Orozco y Berra. 